\title{
8. The Rashomon Effect in Risk Communication during and after Fukushima's Daiichi Nuclear Accident: From Lessons Learned to Areas of Future Research
}

\author{
Claude-Yves Charron
}

\begin{abstract}
Claude-Yves Charron is Fellow and former Director of the Institut d'Études Internationales de Montréal, and Director of the Research Group on Cyber Diplomacy and Cyber Security; he has also been, since 1978, a Professor of International Communications at UQAM, and between 1999 and 2011, Secretary General of the Network of UNESCO Chairs in Communications, ORBICOM, and has conducted 98 research fieldwork projects in the Asia Pacific. Claude-Yves has been doing follow up interviews with key members the Fukushima Nuclear Accident Independent Investigation Commission of the National Diet of Japan and received the "Order of the Rising Sun" in 2019 from the Government of Japan.

charron.c-y@uqam.ca
\end{abstract}

The accident at the Fukushima nuclear complex in 2011 created an unstable decisionmaking environment in which incomplete information and irreconcilable perspectives converged and confronted each other. By starting with the different stakeholders involved, deploying their different "orders of discourse," as Foucault described, ${ }^{1}$ and different narratives, or "intrigues" constructed by each of these perspectives, in Veyne's terms, ${ }^{2}$ the stakeholders were sometimes in negotiation and sometimes in conflict. The National Diet's Fukushima Nuclear Accident Independent Investigation Commission (NAIIC) ${ }^{3}$ elicited different perspectives and mistakes in communication and in the chain of command, from the Prime Minister's Office (PMO), to the regulators, to the Nuclear and Industry Safety Agency (NISA), and from the electricity producer TEPCO headquarters to the operators on the ground. 
The National Diet's NAIIC diagram of the Emergency Communication Protocol offers us a useful frame of reference to understand the risk communication challenges, and the different perspectives involved:

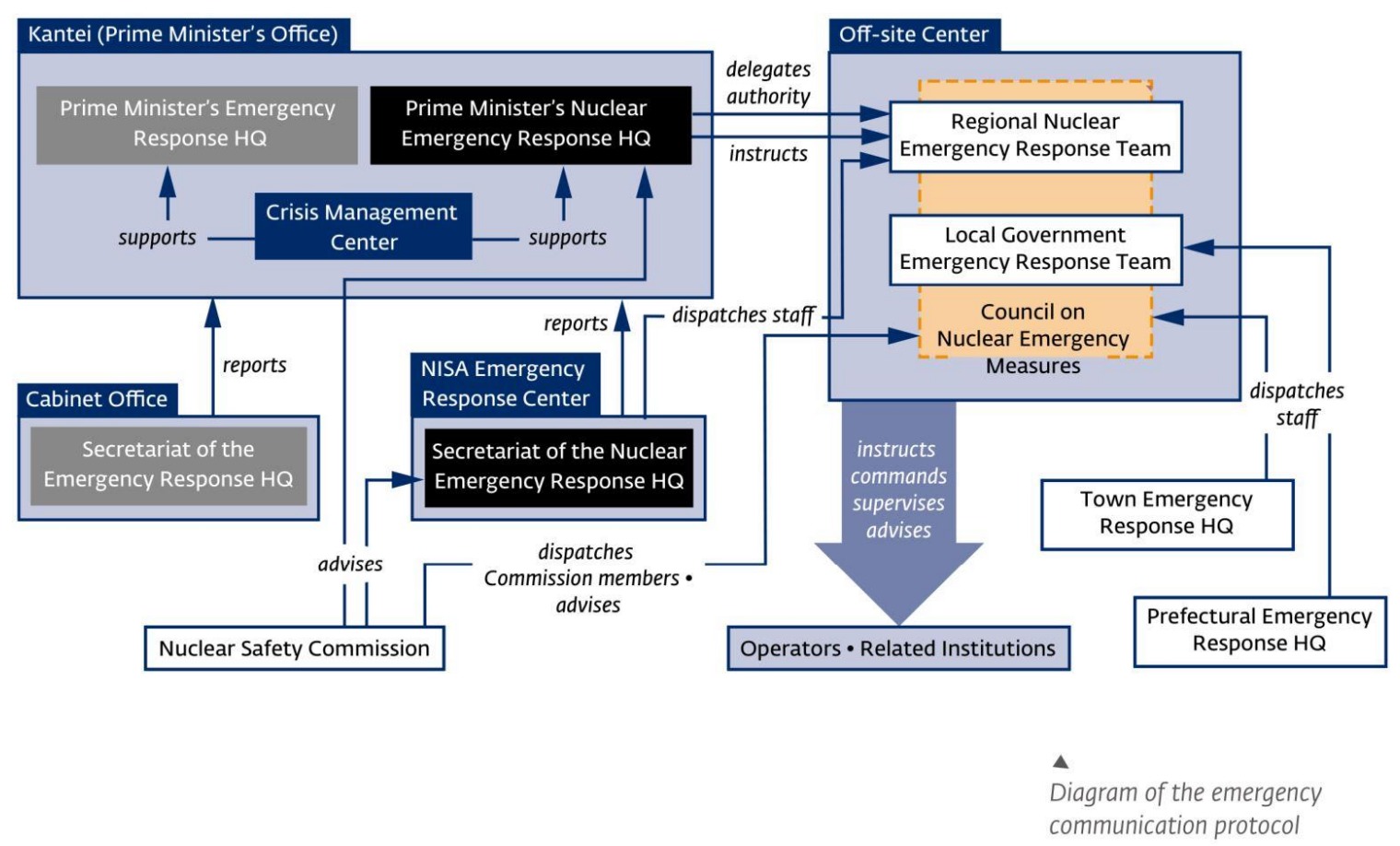

Figure 5. The National Diet of Japan: The Fukushima Nuclear Accident Independent Investigation Commission (NAIIC). (2012). Outline of the organizational framework concerning the nuclear emergency preparedness. (https://www.nirs.org/wpcontent/uploads/fukushima/naiic report.pdf. Used with permission. Rights belong with The National Diet of Japan. $)^{4}$

This emergency communication protocol might be seen as a version of the Rashomon Effect (as Anderson has defined it in 2016), ${ }^{5}$ showing how bewildering it was to the various parties but firing up their networks at the same time. And the intense pressure for closure, so essential to the Rashomon Effect, involved very high stakes within Japan's information political 
economy. You will see that I shall propose a different kind of risk communication after I have reviewed the post-2011 archives here.

The different archives, from the National Diet Library Great East Japan Earthquake HINAGIKU ${ }^{6}$ to TEPCO's "Prompt Report Archives"7 to the Fukushima Prefecture's Archive ${ }^{8}$ and to the Japan's 2011 Disasters Digital Archive $^{9}$ and others, and to the different follow up reports of the International Atomic Energy Agency, offer a very interesting framework for future research on this tragedy, and on the on-going efforts on decommissioning the plant. Each archive was implicitly framed in terms of a legitimation process of its own perspective. Some records are open, some are closed. Japan is also following the standard of 30 years set by the guideline of International Council on Archives.

Allow me to mention that this short essay is a work in progress, not yet completed, being conducted with the utmost respect for the different perspectives and the different stakeholders involved. I must understand their different "orders of discourse," and the "intrigues" constructed by and through their different perspectives in this crisis situation. These notes are also submitted with great respect to my friends living there, and for the evacuees who still face considerable challenges. Less than two weeks after the nuclear accident, I had the honor of being named as representative of the Quebec government and posted in its diplomatic offices in Tokyo. I could follow the information flows, with all the uncertainties associated with the many pieces of the puzzle moving around in the media, with unique perspectives in negotiation and in conflict. 
All the relevant archives which I am describing were established after the tragedy, during the different investigations, and are maintained and active today, with strong associations with other organizations. A visit to the website of the Diet National Archive will give you an impressive introduction to the complexity and the diversity of the different sources involved, making it a potentially "unified" archive for researchers in the future. ${ }^{10}$

On March 7, 2013, the National Diet Library (NDL) started the full-scale operation of the NDL Great East Japan Earthquake Archive, HINAGIKU. ${ }^{11}$ According to its Librarian, Rie Nagasaki: "HINAGIKU is the Searching Portal that enables integrated search and utilization of sound and videos, pictures, websites, etc. about the Great East Japan Earthquake. Its aim is to hand down all records and lessons to future generations and to utilize them for the restoration and reconstruction of the affected areas and for disaster prevention measures." This nickname came from the initial letters of "Hybrid Infrastructure for National Archive of the Great East Japan Earthquake and Innovative Knowledge Utilization." ${ }^{12}$ HINAGIKU offers partial access in nine languages. The language of flowers of hinagiku (daisy) is "future," "hope" or "compathy." "This nickname reminds us of the purpose of the project for reconstruction support" said the Diet's Librarian, Rie Nagasaki.

The assumption of my essay is that risk communication is at the core of any initiative of risk prevention. And to understand risks for the future we need and the Japanese people need to have a very good historic grasp of what really happened at Fukushima in 2011. Most importantly a good historic grasp requires reliable information in a reliable, stable, open archive. With 23,000 deaths, with many others on the path of slow radiation disease, and 
150,000 displaced people, and with the decommissioning of the nuclear stations which still seems to require more and more time, it will be many years before we understand the full consequences of this disaster.

When I arrived in Tokyo in the spring of 2011, I found that many investigations about the nuclear accident were all taking place at once: at the national level, by a Japanese government focusing on TEPCO, by a National Diet investigation parliamentary Commission (NAIIC), and by a private Rebuild Japan Initiative Foundation. Investigations were also being conducted by the International Atomic Energy Agency (IAEA), the American Nuclear Regulatory Commission (NRC), and the Nuclear Energy Agency (NEA) of the OECD. It became a competitive environment, each party trying to capture a different a piece of this fast-evolving cloud of information. Of course, each party was speaking to different audiences and interest groups. Some of the information was just not shared among the parties. This is another meaning of the term risk communication.

From the perspective of the IAEA, its focus was on the importance of the lessons learned. As the (late) Director General Yukiya Amano said in 2015: "Some of the factors leading to the Fukushima accident are not unique to Japan... In fact a key reference for the IAEA 2015 Action Plan... is that "effective international cooperation is vital."'13 From the perspective of the United Nations Office for Disasters Risk Reduction (UNDRR), ${ }^{14}$ which staged the Third UN World Conference on Disaster Risk Reduction at Sendai City, Miyagi Prefecture, Japan, they wanted to reduce the chance of reoccurrence of this kind of accident. The Sendai Framework (2015-2030) was adopted by UN Member States on March 18, 2015 at the Conference on Disaster Risk 
Reduction. ${ }^{15}$ It is a 15 -year, voluntary, non-binding agreement which recognizes that the State has the primary role to reduce disaster risk but that responsibility should be shared with other stakeholders including local government, the private sector and all stakeholders. Here again, risk communication is at the core of risk reduction, not only for Japan, but for the different UN member states.

\section{Perspective of the National Diet's Nuclear Accident Independent Investigation Commission: Lessons Learned during and after the Nuclear Accident}

The most impressive source of information went beyond the technical dimensions of the accidents, and did not remain confidential. That was the Japanese National Diet's "Fukushima Nuclear Accident Independent Investigation Commission" (NAIIC), ${ }^{16}$ chaired by Dr. Kiyoshi Kurokawa, a medical doctor, and former president of the National Science Council of Japan. Indicating how very seriously the Japanese political system viewed this accident, this was the first Independent Commission created in the history of Japan's constitutional government.

Kurokawa's Commission held 900 hours of hearings involving 1,167 people and conducted nine site visits. To gain a global perspective, the Commission dispatched three teams overseas, and included interviews and hearings with experts from the US, France, Russia, Ukraine and Belarus. To assure a maximum degree of information disclosure, all of their nineteen Commission meetings (except the first one) were open to public observation, and were broadcasted on the internet, simultaneously in Japanese and English, to a total of 800,000 viewers in both national and international audiences. 
Having just arrived in Tokyo, I followed some of these meetings on the internet. The Commission was very impressive to an outside observer like me. The Commission also used social media - Facebook and Twitter - and received 170,000 comments. And to better comprehend the viewpoints of the evacuees, three town meetings were held near Fukushima in order to hear first-hand opinions of more than 400 attendees. They also visited twelve municipalities in the evacuated areas. The web site of the Commission is now closed, but all the information has been transferred to the digital archive of the National Diet HINAGIKU. And both the executive summary and the complete report are still both completely accessible online. ${ }^{17}$

The key criticism in terms of risk communication came from the Diet's Independent Commission, framing the issue as a "man-made disaster" involving the main stakeholders:

The TEPCO Fukushima Nuclear Plant Accident was the result of a collusion between the government, the regulators and TEPCO, and the lack of governance by said parties. They effectively betrayed the nation's right to be safe from nuclear accidents. Therefore, we conclude that the accident was clearly "man-made." We believe that the root causes were the organizational and regulatory systems that supported faulty rationales for decisions and actions, rather than issues relating to the competency of any specific individual... Since 2006, the regulators and TEPCO were aware of the risk that a total outage of electricity at the $F$ Daiichi plant might occur if a tsunami were to reach the level of the site. They were also aware of the risk of reactor core damage from the loss of seawater pumps in the case of a tsunami. ${ }^{18}$

\section{My Perspectives on the Roles of Open and Closed Information}

It is popularly imagined outside Japan that important or sensitive information is more tightly held in confidence there than elsewhere in the world. But this accident was unlike anything else which has occurred in Japan since August 1945. A completely new generation with no experience of something on this scale is in charge, in power, and in competition. There 
were also completely new audiences or interest groups paying heightened attention.

Professional newcomers were responsible to a public which did not know them. So even inside Japan observers soon noticed and commented on a pattern of withholding or avoiding or covering up which is not uncommon in other countries, including Canada.

But with so many lives at risk of radiation exposure, the normal slow pace of administrative interaction would not be acceptable; the pressure for closure mounted hour by hour. As the days slipped by, one could see the mistrust slowly building up from the bottom, just the radiation was leaking from the bottom of the reactors. I was in a unique situation of being an outsider, a diplomatic guest and a scholar. This is why I found the slow appearance of open archives, formed out of sensitive and confidential raw material in closed files, so very interesting. Business as usual in Japan was being turned upside down during this crisis, and the following seasons with all the different private, government and parliamentary investigation commissions.

The complementarity between access to archives and local knowledge, and interviews with stakeholders involved in the field is crucial, because of the multiplicity of the different orders of discourse involved, and their different ways they are framed in Goffman's sense. A leader of the TEPCO headquarters in Tokyo, under intense pressure to make decisions, did not always have the same frame as his key officer on the site.

The Independent Commission, the first of its kind in Japan's history, had access to classified documents, and their different interlocutors during the Commission's work understood that they knew about dissociated perceptions. Most individual external scholars 
don't have access to these different frames, but the whole of the Diet's National Archive (HINAGIKU) is dedicated to the accident and provides a frame of reference that is informed by both the open and the closed information.

An enigma remains as to how the Ministry of Foreign Affairs handled its information flow with the American Embassy and all foreign Embassies based in Tokyo, from the "Worst Case Scenario" issue to other sensitive information like the global dispersion of radiated material released from the reactor. This was part of the closed information in the diplomatic order of discourse, but what was conveyed to key parties beyond the open information on the MOFA website?

The pressure of the international media coverage of the accident might have provided for a more important degree of open information than usual. But perhaps due to the scale of the event, the processes it set in motion, the confusion and uncertainty, the coverage was limited to what the key parties were prepared to reveal. For instance, the 400 pages of the 2011 Yoshida Testimony from the key TEPCO manager on the site, was first classified and closed. But after numerous disclosure requests from the media, the government released it in 2014. The Japanese version can now be found in the HINAGIKU Archives, and a French version in Guarnieri and Travadel 2018. ${ }^{19}$

The constant follow-up and collaboration of the International Atomic Energy Agency (IAEA) must have been a plus value here, in terms of the balance between open and closed information at the international level: the Diet's Independent Commission sent teams to 
interview nuclear experts in seven countries to get access to broader information and better interpretation of the nuclear forces at stake.

The delicate balance between open and closed information might remain in Japan, just as it does in every country. But to transform the lessons learned here for other countries, a new balance between the open and the closed worlds is required. As the Director General of the IAEA said in Vienna, this risk situation is not limited to Japan alone, neither with respect to its communications problems, nor to the interface between the regulators and the operators.

I was impressed by the publication of Kadota's On the Brink : The Inside Story of Fukushima Daiichi with interviews with key actors on the site of Fukushima Daiichi, those who were facing the crisis, the information flow problems, and who had to take decisions under the stress of intense pressure for closure ${ }^{20}$ It provides rich and precious local knowledge, coming from the local stakeholders, hearing their perspectives; it gives them the same importance as the other orders of discourse enabling us to understand the intrigues from their perspectives too. Also of special relevance is the 2017 publication of Jobin's “Nuclear Gypsies in Fukushima before and after 3/11," adding the perspectives and challenges of the on-site workers, during the accident, and the thousands of clean up workers, and his analysis the ongoing collective civil actions and law suits by the evacuees and others in 2020 , bringing more perspectives in negotiation and in conflict. ${ }^{21}$ I have also included other important academic and media perspectives in the endnotes, trying to illustrate the diversity of perspectives involved. ${ }^{22}$ 


\section{From Lessons Learned to Areas of Future Research}

The next research I would like to explore depends on my hope that some of the closed files would progressively be opened and thus reveal the evolution of the Rashomon Effect between the different perspectives and different orders of discourse involved:

a) An in-depth analysis of the Yoshida's Testimony, and of all the challenges he experimented in terms of risk communication with the different stakeholders involved. ${ }^{23}$

b) A comparative analysis of the conclusion and recommendations of the three official investigations, from the parliament, the government, and the private sector; my follow up would focus on the implementation of these recommendations.

c) A follow up to the conclusions of the 2016 UN University Fukushima Global Communication Program ${ }^{24}$ on the risk communication challenges after the nuclear disaster; what has been implemented during this complex recovery process.

d) A follow up of the 2020 Disaster Prevention and Relief Division of the Ministry of Land, Infrastructure, Transportation, Tourism's “Nankai Trough Mega Earthquake Operation Plan."25

e) A follow up study to the four action-priorities of the UN Sendai Framework (2015-2030) with a special focus on the second one, namely "strengthening risk governance to manage disaster risks."26 
f) And, even if it would take more time, I would do a follow up study on the communication risk management in each of the stakeholders elicited within the NAIIC's diagram of the communication emergency protocol (diagram presented in the opening of this essay). Have the parties adjusted to the new risk elicited around the forecast for the "Nankai Trough"? The government's Earthquake Research Committee, chaired by professor Naoshi Hirata of the University of Tokyo, announced on February 9, 2020 that the probability of a magnitude 8 or 9 earthquake occurring within the next thirty years in the Nankai Trough had risen slightly from last year from 70 to 80 percent. ${ }^{27}$ That forecast creates a much more important risk in terms of earthquake, and consequent tsunamis and nuclear accidents than Fukushima.

In my future research I expect to find a lot of intrigues appearing in other Rashomon Effects with different perspectives in complex and unstable decision-making environments. But through this research we can build on the lessons learned from Fukushima regarding leadership, governance, disaster resilience, and crisis management; perhaps this will steer us away from another "man-made disaster."

The parties caught in the spotlight by the tsunami and reactor accident in 2011 had to mobilize all their resources and constantly calculate the risk to their reputations just to avoid being defeated in the coming contest over information. It was the perceived risk to their credibility and reputation, not simply their chance to score against the other parties, which guided most of them through that period of complete uncertainty. Thus, we might see their risk communication, and the archival record which they were carefully building and guarding, as 
being at the heart of the Rashomon Effect in the Fukushima incident, especially in the context of the uncertainties of a next major earthquake and tsunami and other potential nuclear accidents much more important than in Fukushima, related to the "Nankai Trough." 


\section{Annex I}

National Diet Library Great East Japan Earthquake Archive HINAGIKU. https://kn.ndl.go.jp/\#/. Images used with permission. Rights belong with The National Diet Library of Japan.

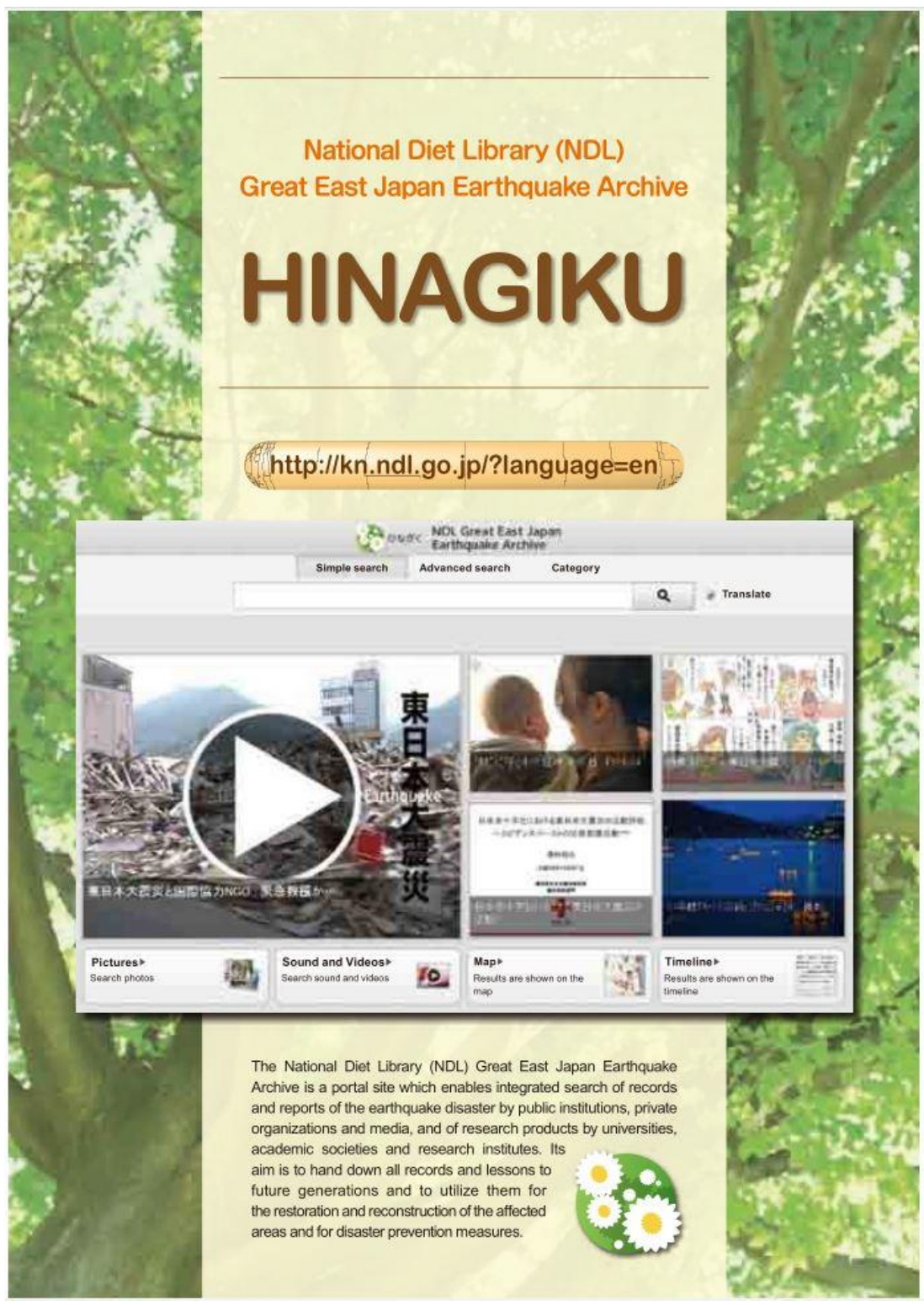




\section{What is}

the NDL Great East Japan Earthquake Archive (HINAGIKU)?

The "Seven Principles for the Reconstruction Framework" " and the "Basic Guidelines for Reconstruction in response to the Great East Japan Earthquake " formulated by the Japanese government emphasized the need to develop a system for collecting, preserving and providing records and lessons of the disaster caused by the earthquake and subsequent tsunami and nuclear accident, and to construct a mechanism for utilizing them in an integrated manner, accessible to everyone around the world.

In accordance with the above national policy, the NDL constructs the "NDL Great East Japan Earthquake Archive" in cooperation with various organizations inside and outside Japan to collect and preserve records of the earthquake for Japan as a whole and to provide them to people all over the world.

\section{Whole image of the NDL Great East Japan Earthquake Archive}

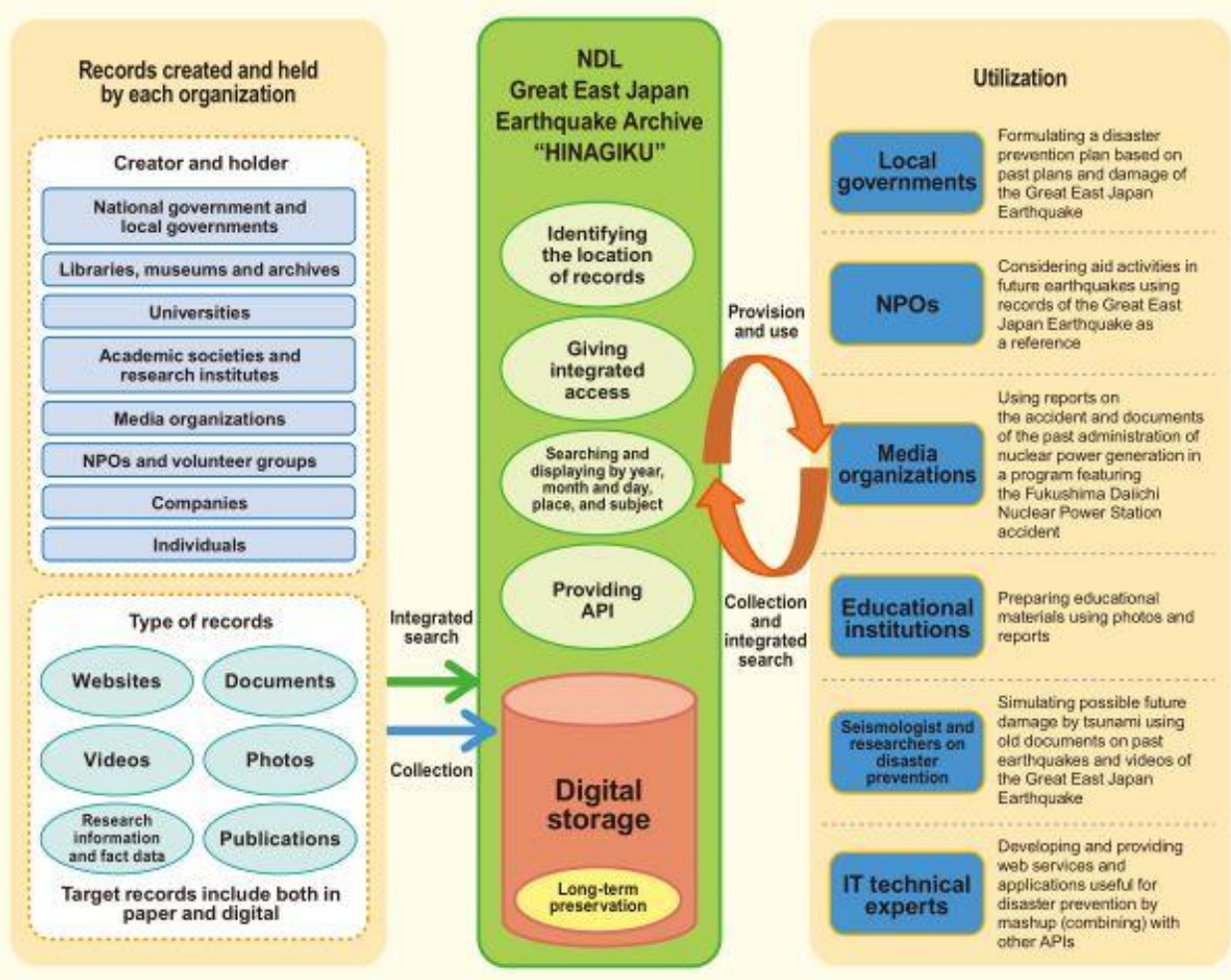

$\uparrow$ Formulated at the fourth session of the Reconstruction Design Council in Response to the Great East Japan Earthquake (May 10, 2011)

" 2 Reconstruction Headquarters in response to the Great East Japan Earthquake (The 5th) (formulated on July 29, 2011, revised on August 11, 2011)

You can see the documents above on the "HINAGIKU". 

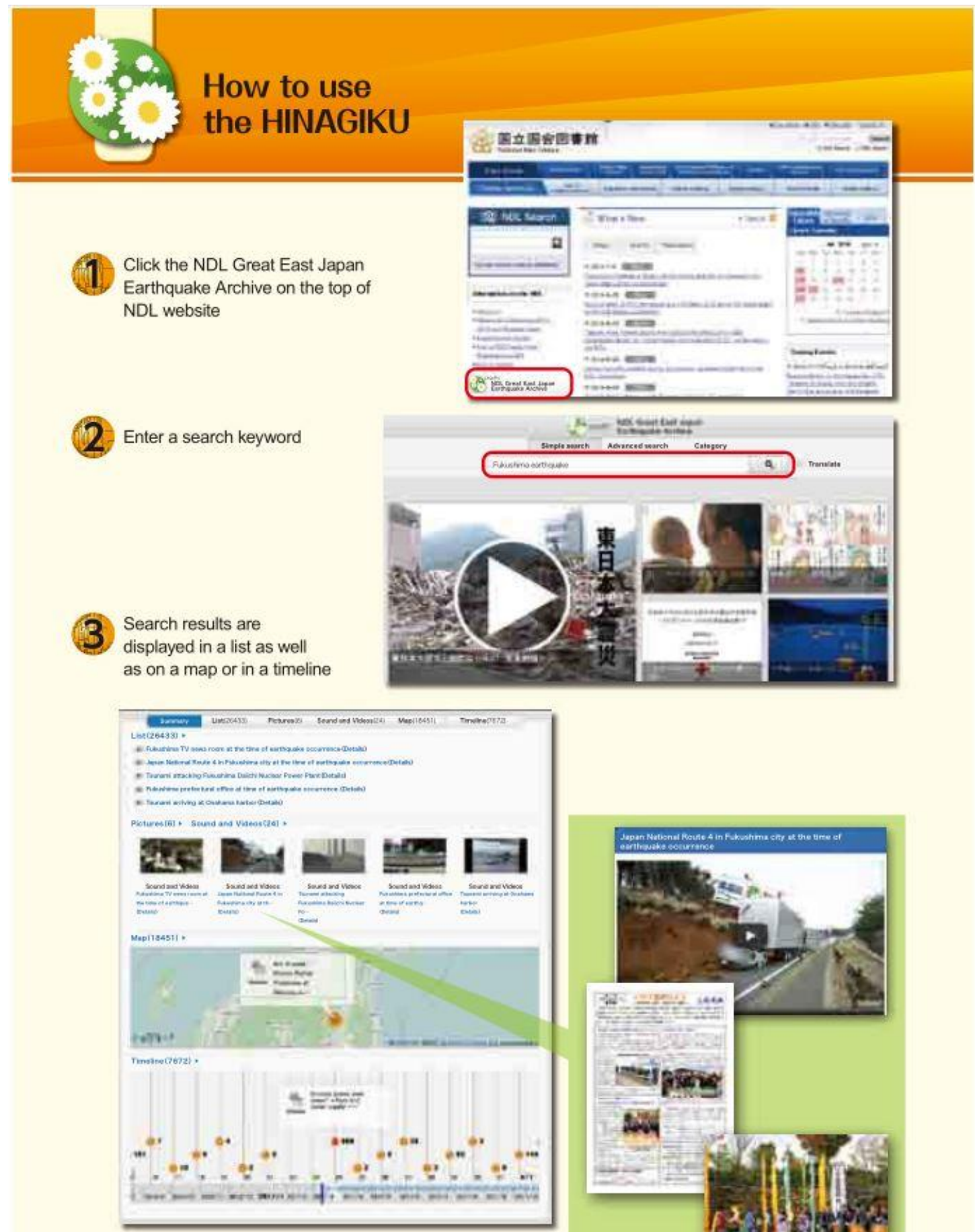

4. Reports, photos and videos are available

(For some of them, only the index information is available)

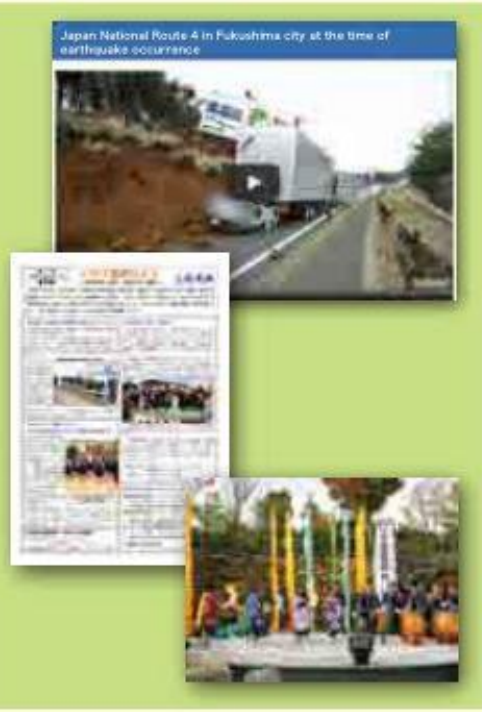




\section{The NDL collects,} preserves and provides records in cooperation with the following organizations:

\section{Local government}

Hachinohe City, Misawa City, Oirase Town, Hashikami Town

\section{Libraries}

Fukushima Prefectural Library / Higashimatsushima Library / Iwate Prefectural Library / Kobe University Library / Saitama Prefectural Urawa Library/Sendai Shimin Library

\section{Research institutes}

Edwin O. Reischauer Institute of Japanese Studies at Harvard University / International Research Institute of Disaster Science of Tohoku University / Japan Atomic Energy Agency / Japan Science and Technology Agency / National Institute of Informatics / Research Center for Cooperative Civil Societies of Rikkyo University / Tohoku Gakuin, etc.

\section{Media organizations}

Fuji Television Network, FNN (Fuji News Network) / Kahoku Shimpo Publishing / NHK (Japan Broadcasting Corporation), etc.

\section{Photo and video sharing and search services}

Google / Yahoo Japan

\section{Companies and various organizations}

Aomori Digital Archive Consortium / Japan NGO Center for International Cooperation / National Women's Education Center for Japan / Red Cross Nuclear Disaster Resource Center/ The Great East Japan Earthquake Archive Fukushima, etc.

(in alphabetical order, as of July 2014)

The NDL will enhance the nationwide digital archive by encouraging more and more institutions to be collaboration partners, and working together to collect and preserve records related to the earthquake.

Thank you very much for your kind understanding and continuous cooperation that helps us to collect and preserve records of the Great East Japan Earthquake.

\section{Why "HINAGIKU"?}

The "HINAGIKU", another name of the NDL Great East Japan Earthquake Archive, is a partial acronym of the "Hybrid Infrastructure for National Archive of the Great East Japan Earthquake and Innovative Knowledge Utilization." In the language of flowers, hinagiku (daisy) - meaning "future," "hope" and "sympathy" - includes the aim of the project supporting the earthquake recovery.

\section{的国立国会図書館 National Diet Library, Japan}

\section{な部く}

Digital Information Distribution Division, Digital Information Department, National Diet Library 1-10-1 Nagata-cho, Chiyoda-ku, Tokyo, 100-8924 


\section{Annex II}

From NHK World Prime, the documentary, 3/11 - The Tsunami : The First Three Days:

Using footage shot at the center of the March 2011 Great East Japan Earthquake and tsunami, we bring you a story of horror and heroism during one of history's worst catastrophes. Vast areas along Japan's Pacific coast were devastated. Entire communities were washed away and residents were forced to evacuate. An accident at the Fukushima Daiichi Nuclear Power Plant created a radioactive no-man's-land. But in the days that followed, amid the chaos and confusion, countless people sprang into action to assist victims and search for survivors. ${ }^{28}$

The author acknowledges, with deep gratitude, on-going discussions and exchanges with the editor of this collection Robert Anderson over many years, and his specific comments on this essay.

${ }^{1}$ Michel Foucault, L’Ordre du Discours (Paris : Éditions du Seuil, 1971).

2 Paul Veyne, Comment on Écrit l'Histoire (Paris : Éditions du Seuil, 1971).

${ }^{3}$ The Fukushima Nuclear Accident Independent Investigation Commission (NAIIC) (Tokyo: National Diet of Japan, 2012).

${ }^{4}$ National Diet of Japan, 35.

${ }^{5}$ Robert Anderson, "The Rashomon Effect and Communication," Canadian Journal of Communications, Vol 41 no 2 (2016): 249-69.

${ }^{6}$ National Diet Library Great East Japan Earthquake Archive, HINAGIKU, (2020). https://kn.ndl.go.jp/\#/

7 “Prompt Report Archives (2020)," Tokyo Electric Power Company Holdings (TEPCO), accessed July 11, 2021, https://www.tepco.co.jp/en/hd/newsroom/reports/archives/indexe.html

8 Japan Disasters Digital Archive, Harvard University: www.jdarchive.org 
${ }^{9}$ Yukiya Amano, Report of the Director General: The Fukushima Daiichi Nuclear Accident (International Atomic Energy Agency, 2015).

${ }^{10}$ National Diet Library Great East Japan Earthquake Archive.

${ }^{11}$ National Diet Library Great East Japan Earthquake Archive.

12 Rie Nagasaki, “National Diet Library's Efforts to Build the Great East Japan Earthquake Archive and Its Current Status," Future Libraries: Infinite Possibilities, Session 146 (Singapore: IFLA WLIC Conference, 2013).

${ }^{13}$ Amano, Report.

14 "Implementing the Sendai Framework for Disaster Risk Reduction," UNDRR, accessed July 11, 2021, https://www.undrr.org/implementing-sendai-framework/what-sendaiframework

15 "Sendai Framework for Disaster Risk Reduction 2015-2030," UNISD, accessed July 11, 2021, https://www.preventionweb.net/sendai-framework/sendai-framework-for-drr

16 The Fukushima Nuclear Accident.

${ }^{17}$ National Diet Library Great East Japan Earthquake Archive.

18 The Fukushima Nuclear Accident.

${ }^{19}$ Franck Guarnieri, and Sébastien Travadel, Un Récit de Fukushima: Le Directeur Parle (Paris: Presses Universitaires de France, 2018). Guarnieri, "What Fukushima Can Teach Us in Terms of Crisis Management," Philonomist: https://www.philonomist.com/en/interview/challenge-isnt-avoid-disasters-accept-theyllhappen

${ }^{20}$ Ryusho Kadota, Akira Tokuhiro, and Simon Varnam, On the Brink: The Inside Story of Fukushima Daiichi (Kurodahan Press, 2014).

${ }^{21}$ Paul Jobin, "Nuclear Gypsies in Fukushima before and after 3/11", in Nuclear Portraits: Communities, the Environment, and Public Policy, ed. Laurel MacDowell (University of Toronto Press, 2017).

22 "Situation of the Evacuees," Fukushima on the Globe, accessed July 11, 2021, http://fukushimaontheglobe.com/the-earthquake-and-the-nuclear-accident/situation-of-theevacuees. "Resource Library," Fukushima on the Globe, accessed July 11, 2021, http://fukushimaontheglobe.com/resource-library. Sachiko Inoue, "Passing on the Lessons of 
the Great East Japan Earthquake to Future Generations: The National Diet Library Great East Japan Earthquake Archive," Transform Libraries, Transform Societies, Session 233 (Kuala Lumpur: IFLA WLIC 2018 Conference), Government Information and Official Publications. “National Diet Newsletter," National Diet Library Digital Collections, accessed July 11, 2021, https://www.ndl.go.jp/en/publication/ndl newsletter/220/22005.html. The Independent Investigation Commission on the Fukushima Nuclear Accident, "The Fukushima Daiichi Nuclear Power Station Disaster: Investigating the Myth and the Reality," ed. Mindy Kay Bricker (Routledge, 2014).

${ }^{23}$ Reiji Yoshida, "Yoshida Transcripts on Fukushima Nuclear Crisis Released," Japan Times, September 11, 2014, https://www.japantimes.co.jp/news/2014/09/11/national/yoshida-transcripts-on-fukushimanuclear-crisis-released/.

${ }^{24}$ Ana Mosneaga, Akiko Sato, and Nicholas Turner, Fukushima Global Communication Programme Final Report (United Nations University Institute for the Advanced Study of Sustainability, 2016).

25 “Find Out! Japan's Preparations for Earthquakes," Japan Ministry of Land, Infrastructure, Transport and Tourism, accessed July 11, 2021, https://www.mlit.go.jp/river/earthquake/en/nankai/index.html.

26 "Implementing the Sendai Framework."

27 “Gov't Committee to up Estimate of Major Nankai Trough Quake to 70-80\% in next 30 Years," The Mainichi, December 29, 2017, https://mainichi.jp/english/articles/20171229/p2a/00m/0na/002000cQ

28 3/11 - The Tsunami : The First Three Days, NHK World Prime, broadcast January 8, 2021, https://www3.nhk.or.jp/nhkworld/en/ondemand/video/3016087/?cid=wohk-fbin_ca_p1_feed_vod_20210118_20210214_Tsunami_Ep1_2021Jan_Documentary_ad_dps202101-1 